\title{
Using network analysis to analyse the complex interaction of factors causing the failure of small-scale water infrastructure (SWI) in the rural areas of South Africa
}

\author{
DC Sambo ${ }^{1,2 *}$, A Senzanje $^{1}$ and K Dhavu ${ }^{3}$ \\ 'Bioresources Engineering, School of Engineering, University of KwaZulu-Natal, P Bag X01, Scottsville, 3209, Pietermaritzburg, South Africa \\ ${ }^{2}$ University of Venda, P Bag X5050, Thohoyandou, South Africa \\ ${ }^{3}$ Agricultural Research Council, Institute of Agricultural Engineering, P Bag X519, Silverton 0127, Pretoria, South Africa
}

\begin{abstract}
Some parts of the rural areas of South Africa are receiving water services below the legislative standards stipulated in the Water Services Act (1997) of South Africa. This is because small-scale water infrastructures (SWI), including standpipes, handpumps and windmills, are failing to supply adequate water in rural communities for various activities that enhance their livelihoods. This is due to technical, community, institutional, and environmental factors. Literature indicates that these factors are complex in nature. However, research on their complex interactions has been limited. Therefore, the complex interactions of the factors causing SWI failure were investigated and analysed in this study. A qualitative research approach was employed to investigate the factors that cause failure of SWI. The network approach combined with graph theory and the community structure method were used to generate a theme and domain network that allowed for a systematic analysis and interpretation of the causes of SWI failure in the study area. The major causes of failure identified include: (i) the use of a top-down approach to implement water projects in rural communities without consultation, (ii) sharing of SWI in high numbers due to the limited number of SWI available/functional, resulting in overloading and increased breakdowns, and (iii) drying up of water sources due to poor siting leading to vandalism of SWI. Overall, the causes of SWI failure are as a result of the complex interactions of different categories of factors. The theme and domain network is a powerful tool that can be used represent and analyse the complex interactions. It is therefore imperative for interventions aiming to improve rural water supply to analyse the complex interactions of the causes of SWI failure to understand the underlying problems at a level of a system, in order to propose suitable solutions.
\end{abstract}

Keywords: network analysis, operation and maintenance, rural communities, small-scale water infrastructure

\section{INTRODUCTION}

Improved access to water supply contributes to enhanced rural livelihoods in poor and developing countries (Dungumaro and Madulu, 2003; Hunter et al., 2009). This is because rural communities use water for activities that generate income and ensure their food security (Adank, 2006). It is therefore imperative to ensure that they have improved access to water. This is recognised at a global and national scale, driven by the Sustainable Development Goals (SDG) target to achieve universal access to improved water sources (IWS) (Hutton, 2013). In the context of the SDG, IWS refer to water infrastructure used by rural communities to supply safe and affordable water. For the purposes of this paper, the definition of IWS by Senzanje et al. (2012) as smallscale water infrastructure (SWI) is preferred. Senzanje et al. (2012) defines SWI as any technical hardware used by rural communities in managing water resources for domestic, agricultural and rural development purposes, and is operated on a small-scale. Examples of SWI include; hand-pumps, small reservoirs (dams), standpipes, windmills and protected shallow wells. However, it has been shown that SWI are failing to supply sufficient quantities of good quality water in rural communities (Mann, 2003; Rietveld et al., 2008; Boshoff, 2009;

To whom all correspondence should be addressed.

而 +27159628736

e-mail: calvin.sambo@univen.ac.za; calvinsambo@gmail.com Received 7 June 2016; accepted in revised form 11 June 2018.
Graciana and Nkambule, 2012). It is estimated that poor and developing countries in sub-Saharan Africa, including South Africa, have the lowest rates of access to SWI in the world, with approximately 278 million people in rural communities without access to safe and affordable water sources to meet their daily water needs (Mann, 2003; Marks and Davis, 2012). Many of the rural SWI are in a state of disrepair and are nonfunctional due to a variety of factors (Mann, 2003; Rietveld et al., 2008). This negatively impacts on rural livelihoods.

Given the importance of improving access to water in rural communities, many researchers have conducted studies to understand the reasons why SWI fail (Mann, 2003; Rietveld et al., 2008; Boshoff, 2009; Graciana and Nkambule, 2012). The studies did well in documenting the factors that cause SWI failure. However, they lacked a detailed analysis of the factors to inform those responsible (for SWI) in order to fully understand the underlying problems and propose long-term sustainable solutions. Thus it is still reported that rural communities have patchy access to water as a result of SWI failures (Kuscu et al., 2009; Šadzevičius et al., 2013). The causes of SWI failure fall under broad categories of factors, namely; technical, institutional, community/social, financial, and environmental. According to Graciana and Nkambule (2012), based on their study conducted in the rural communities of Swaziland, technical and community factors were the main causes of SWI failures compared to environmental, institutional and financial factors. Some studies focused on one category of factors; mostly technical factors (Mann, 2003; Rietveld et al., 2008). However, a 'single category approach' doesn't yield solutions that ensure 
long-term access to water in rural communities as underlying issues resulting in SWI failure are overlooked. This is because water-related issues are complex in nature (Harvey and Reed, 2004), therefore exhibiting a complex system. Bezuidenhout et al. (2013) state that factors occurring in a complex system are interconnected and interact, resulting in failures in the system. Given the complex nature of water-related issues, factors that affect SWI failure are interconnected and interact, causing failure of SWI. Therefore, one category of factors should not be addressed in isolation from the other factors. To address SWI failure, one should employ a holistic approach that takes into account the complex nature of the factors that cause SWI failure. This will result in suitable and long-term solutions that will ensure that rural communities have sustained access to water services.

\section{Complex systems analysis}

Complex systems consist of a variety of interconnected factors, which jointly exhibit emergence and behaviour that cannot be explained by simply analysing or studying a single category of factor in the system (Sterman, 2006). This is because the interaction of the different factors results in complexity that is manifested at the level of the system (Cilliers, 1998). Therefore, to understand the complexity resulting from the interactions of the factors one should employ an approach that is able to analyse the multitude of interconnected factors in the system. Such an approach should allow for the identification of critical factors that result in failures and success in the system.

A cause-effect tool, such as the fishbone can be used to analyse interactions of factors in a system (Watson, 2004). The tool can graphically and systematically illustrate the root causes for a specific effect. The effect can be either positive (an objective) or negative (a problem). The causes (a problem) are those that contribute to the effect, which then allows corrective measures to be taken. Categories of factors are established beforehand and the causes are populated under each category. As a result, the analysis will be specifically focused on a single category of factors. Such a tool completely overlooks the interaction of the variety of factors in the different categories (Bezuidenhout et al., 2013). Therefore, to unlock the potential for improving a complex system, suitable methods must be used to capture the complexity of the system. Once this has been captured, critical areas for improvement can be identified in the system.

Researchers have attempted to improve complex agricultural systems using various techniques to identify problems and apply corrective measures (for example, McClanahan et al., 2009; Fairweather, 2010; Bezuidenhout et al., 2012; Bezuidenhout et al., 2013). However, problem identification in a complex system can be more difficult than solution generation (Rosenhead and Mingers, 2001). In the context of agricultural complex systems, Fairweather (2010) used cognitive mapping to illustrate the opinions of dairy and kiwi-fruit farmers in New Zealand. A qualitative research approach was used to collect data and meta-analysis was used to combine all the individual maps into a single map that characterises each sub-system. Cognitive mapping models point towards how farmers perceive their systems and facilitate the identification of problems and opportunities to improve the system. Social network analysis can also be used to analyse complex systems by mapping stakeholder perceptions. Martinez-Lopez et al. (2009) state that maps generated for social network are prone to subjectivity during data collection.
Fairweather (2010) recommends the use of Q-methodology to reduce subjectivity. Bezuidenhout et al. (2013) emphasize that although the Q-methodology is recommended to reduce subjectivity, data analysis and resultant maps may also be prone to biases from the researcher. Cross et al. (2002) recommend a network analysis approach for analysing complex systems, because it utilizes techniques from algebra, graph theory and statistics, and can be used to visually represent a multitude of issues and factors associated with a complex system.

Graph theory can be used to classify nodes as central, or more important, in the system, based on their connection with other nodes in the system (Telesford at el., 2011). The most common methods used in the graph centrality approach include the degree centrality, betweenness centrality and closeness centrality (Freeman, 1977 and Freeman, 1979). However, proper use of the approach is dependent on the objective and the data available (Telesford at el., 2011). To enhance analysis of the network, Bezuidenhout et al. (2013) recommends use of the community structure method to derive different communities (themes) defined by the interaction of factors in the network. As a result, the network is divided into smaller compartments that can be analysed, and the important areas in the network defined (Fortunato, 2010). Both the graph centrality method and community structure methods offer great advantages when combined, depending on the objective to be achieved, as they are powerful tools to systematically assess and identify problem areas and areas for improvement in the network (Bezuidenhout et al., 2013). Therefore, combined with the network analysis approach they can be used to represent the complex interactions of factors in a complex system for a detailed, systematic analysis of the issues resulting in failures in the system in order to propose sustainable solutions.

To date, there have been no reported studies that analysed the complex interaction of the different factors that cause failure for rural SWI as a complex system using the network analysis approach. Therefore, the aim of the study reported in this paper was to investigate and analysis the complex interactions of the causes of failure for SWI in Nebo Plateau, Limpopo Province, South Africa, using a combination of a qualitative research techniques and the theme and domain network approach.

\section{MATERIALS AND METHODS}

The study was conducted in Makhudutamaga Local Municipality (Nebo Plateau), Sekhukhune District, Limpopo Province, South Africa (Fig. 1). The municipality consists of 31 wards and 143 villages, with an estimated population of 283956 (IDP, 2018). The assessment was done in 13 wards. The known dominant SWI types used by the communities in these wards are boreholes, small reservoirs and shallow wells (IDP, 2012). Although the SWI mentioned exist in the area, it is estimated that $47 \%$ of the population in the Makhudutamaga Municipality receives water below the legislated standard (physical access, affordability and, water quantity and quality) stipulated in the Water Services Act of 1997 (IDP, 2012).

However, there have been speculations that the number may be slightly higher (IDP, 2012).

The growth point of the municipality is Jane Furse, where most of the government services are offered to the community. The Mukhudutamaga Municipality does not have the function to provide water supply services to the rural communities. Water provision in the municipality is the responsibility of the 


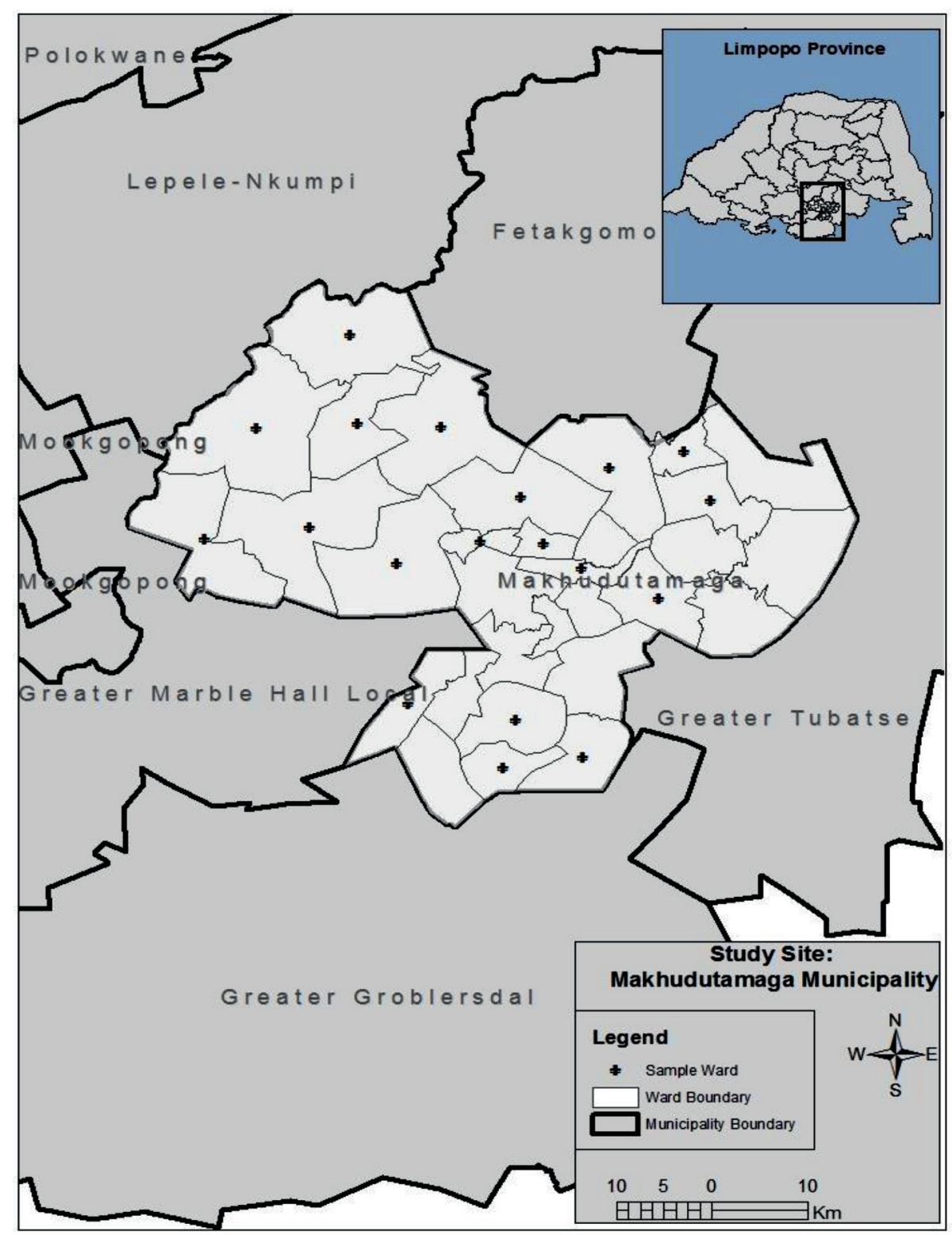

Figure 1

Location of study site

Sekhukhune District Municipality as the sole Water Services Authority (WSA) and Water Services Provider (WSP). The district municipality is also the de facto legal custodian of the SWI.

The study was undertaken during September and October of 2012 to capture the water problems experienced during the day, and specifically during the dry months of the year. The study had two stages, firstly, a qualitative research approach was used to investigate the causes of failure for the SWI, using interviews, visual observation and secondary data (review of literature). Secondly, an analysis of the cause of failure was done using the theme and domain network approach.

\section{Key informant interviews}

Key informant interviews were carried out with different stakeholders involved in the operation and management of SWI. The objective of the interviews was to identify the causes of failure of SWI in the study area from the stakeholders' perspective. Information gathered in the interviews was based on qualitative explanatory perception of the interviewees. The use of qualitative methods such as interviews enabled the researcher to explore and elaborate on different issues in question in a systematic manner (Silverman, 2002). The local language (Sepedi) was used for the stakeholders that could not understand English. A total of 33 stakeholders were interviewed (see Table 1). The number of stakeholders interviewed depended on their availability and accessibility at the time of the study. The sample size was found to be adequate and meaningful. This is because certain issues raised by stakeholders overlapped and were echoed by most participants. Therefore, a greater sample size would have resulted in redundancy and saturation of issues (Bowen, 2008). The interview was guided by a set of questions which provided a platform for a rich exploration of complex issues relating to failure of SWI. The questions were semi-structured 
TABLE 1

List of stakeholders interviewed

\begin{tabular}{|l|l|c|}
\hline Institution/organisation & Designation & Number \\
\hline Department of Water Affairs (Limpopo) & Director: Groundwater & 1 \\
\hline Limpopo Department of Agriculture & Extension officers & 4 \\
& Researchers & 2 \\
\hline Sekhukhune District Municipality - Water Services & Technical staff & 5 \\
\hline Traditional Authority & Head man & 1 \\
\hline Mvula Trust (NGO) & Manager: Water Management & 1 \\
\hline Tsogang (NGO) & Director & 1 \\
\hline Village water committee (VWC) Member - Wonderboom & Chairman & 1 \\
\hline Community & Treasurer & 1 \\
\hline Total & Community members & 16 \\
\hline
\end{tabular}

to allow the interviewees to explain the issues according to their understanding and observation in the study area. Furthermore, the explanations provided by the interviewees prompted further probing of issues raised. The open-ended questions asked to the interviewees included the following;

- According to your knowledge, how many SWI are functional and dysfunctional in your community or area of service?

- What are the causes of failure of SWI in your community or area of service?

- Who do you think should take responsibility for the failure of SWI?

- What can be done to minimize the failure of SWI?

- Are there any other SWI related issues which you feel we have missed?

During the interview, the researchers listened attentively to the response provided by the interviewee to each question and noted the important issues relating to the failure of SWI. When the researchers did not understand certain issues explained, follow-up questions were asked to probe for further explanation and clarification. This enhanced the understanding of the issues raised by the interviewee. The explanations provided by the interviewee aided the researchers to preliminarily categorise and link the causes of failure.

To complement the interviews and further enhance the understanding of the researchers in the development of the network, physical field visits were done in some communities. Transect walks were done in those communities where there were people available to guide the researchers. Systematic walks across the communities observing the existing SWI (in-use and out-of-use), how they are used by the respective communities and asking of further questions was done during the transect walks. Furthermore, key strategic documents used by the Water Services Provider (WSP) were reviewed to get more information on the strategic approaches adopted by the municipality (district and local) in providing waterrelated services in the study area. The information acquired was analysed and assisted in the construction of the theme and domain network for further analysis.

\section{Data analysis and construction of the network}

The study employed a triangulation method to derive factors that caused SWI failure from the rich information collected during the interviews, physical field visits and literature review. Due to the large number of factors derived, they were classified under different categories. As a result, the factors were organised and easy to manage when subjected to a systematic analysis (Watson, 2004). The categories of factors were derived as a result of a review of research studies which addressed water-related issues in rural communities (Harvey and Reeds, 2004; Graciana and Nkambule, 2012; Rietveld at el., 2012; Swan, 2012). Most of the studies focused on one or two categories of factors. The categories of factors are listed and briefly described below:

- Technical factors: involve issues that have to do with the technology used to supply water to the rural communities, e.g. selection of appropriate water lifting technology, operation and maintenance $(\mathrm{O} \& \mathrm{M})$ and availability of spare parts.

- Community factors: involve issues that have to do with the rural communities using the SWI, e.g., demand for improved services and sense of ownership.

- Institutional factors: involve issues that have to do with the institutions or organisations responsible for the management of SWI, e.g., government responsibilities and implementation of policies and funding

- Environmental factors: involve issues that have to do with the effects of the environment on water supply, e.g., water quality and protection of water source.

As mentioned in the introduction section, the different factors that cause SWI failure are complex in nature. To depict their complex interactions, the researchers explored different approaches used to analyse complex systems (for example; Watson, 2004: Fairweather et al., 2006: McClanahan et al., 2009; Fairweather, 2010; Bezuidenhout et al., 2012; Bezuidenhout et al., 2013). The network analysis approach was preferred due to its ability to capture complex interaction of factors in a system (Bezuidenhout et al., 2013). It can also be combined with other methods to enhance analysis of the factors. Figure 2 illustrates a summary of the steps taken to generate a theme and domain network.

In applying the approach, the researchers considered the following key questions: (i) 'What are the considered nodes in the network?'; (ii) 'What are considered links or connections in the network?'; (iii) 'Are there strong and weak links differentiated?' and (iv) 'Are there themes in the network?' (Telesford et al. 2011). These questions were important as they guided the connection of factors and use of the appropriate methods employed to identify the critical 


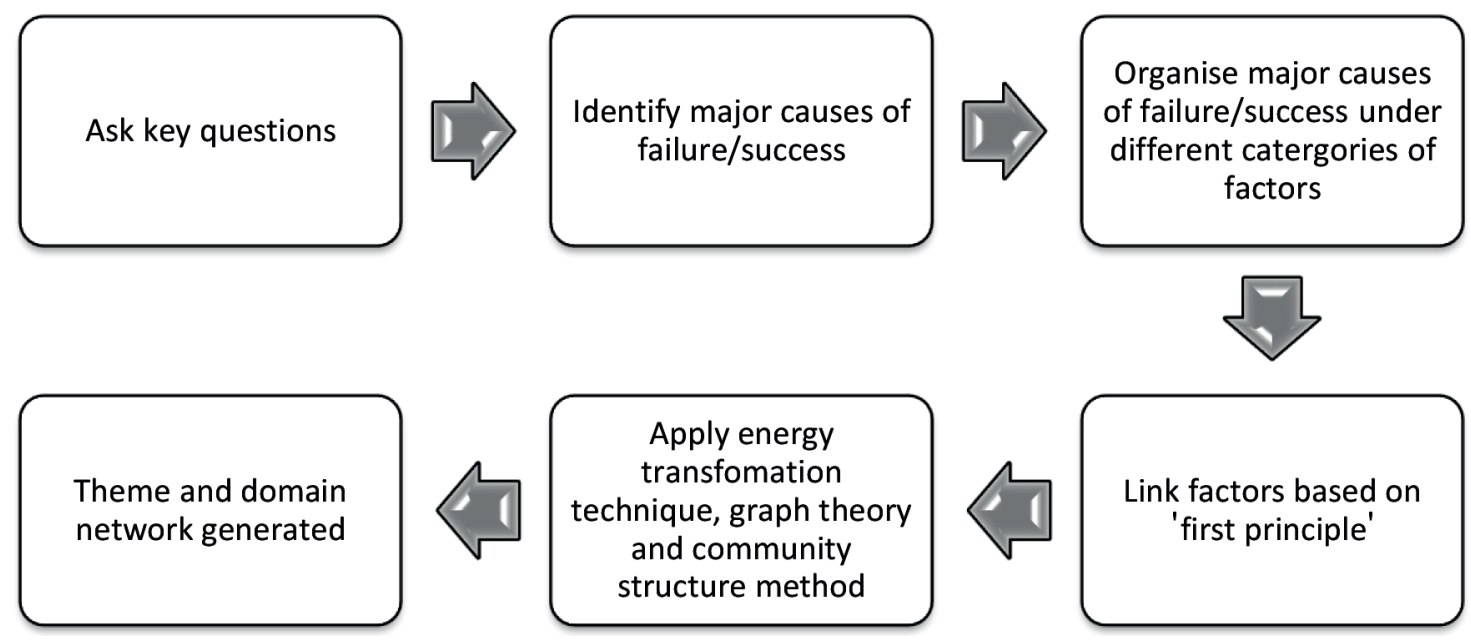

Figure 2

Summary of key steps used to generate the theme and domain network

points in the network. Therefore, the different coloured nodes shown in Fig. 2 represent the factors that cause failure of SWI. The different colours of the nodes represent the categories as follows: technical factors (yellow node), community factors (green node), institutional factors (blue node) and environmental factors (red node). The nodes were connected by the researchers informed by the rich information collected based on 'first principles'. Bezuidenhout et al. (2013) refers to this as a connection between factors based on their immediate direct cause-effect relationship (interaction). For example; 'lack of maintenance' was directly linked to 'poor condition' due to their immediate cause-effect relationship.

Microsoft (MS) Notepad software was used to create the file with the connections. The file was exported to Pajeck

(Version 3.2) to generate a network that visually represented the connectedness and interaction of the different categories of factors (Batageli and Mrvar, 2016). Pajek is software specially designed to generate, analyse and manipulate complex networks (Huisman and Van Duijn, 2003; Xu et al., 2010; Batageli and Mrvar, 2016). The network was generated using the Kamada-Kawai (1989) energizing transformation. The Kamada-Kawai (1989) energizing transformation technique positioned closely related factors close to each other in the network based on their connections. As a result, the network visually represented the interactions of the factors. However, this did not allow for a systematic analysis of the network. As a result, the graph theory method was employed to enhance the network to graphically illustrate critical points based on their connection with other categories of factors (Telesford at el., 2011). The method was combined with the community structure method which was used to determine different themes as a result of the interactions of the different factors in the network (Telesford et al., 2011). The community structure method allowed for the nodes of the network to be clustered into overlapping sets that were better internally connected, hence helping in understanding the linkages. As a result, 4 themes were identified that allowed for analyses of important areas in the network (Fortunato, 2010). The combined methods allowed for a systematic analysis of the network and identification of critical points that cause failure of the SWI in the study area (Bezuidenhout et al., 2013).
Despite the study having limitations due to constraints posed by time, budget and availability of individual stakeholders, it is still believed that the information obtained is adequate and valid enough to give a true picture on the causes of failure for SWI in the study area because of the diverse range of stakeholders sampled. The researcher is aware of the dynamic nature of issues related to SWI use and management. Consequently, the issues raised by the stakeholders interviewed may have been dependent on the time of the study. This is a phenomonen that will need further research over an extended period of time.

\section{RESULTS AND DISCUSSION}

This study found that there are many different causes for the failure of SWI in Nebo Plateau. For ease of analysis, the causes of failure were categorised under technical, environmental, community and institutional factors. These factors interact with each other and the interactions show unique thematic problems found in the study area.

\section{Categories of causes of SWI failure}

\section{Technical factors}

The water lifting technology in use for the SWI and its design is failing the rural communities of Nebo Plateau, as depicted in Fig. 3. This is because SWI break down due to a number of technical factors, including but not limited to: (i) wornout bearings, (ii) burst pipes, (iii) the use of poor quality material and (iv) the lack of maintenance. The failure of SWI is exacerbated by the lack of locally available spare parts to facilitate timely repair. The lack of spare parts is caused by the selection and use of internationally manufactured technology for the development of SWI in the study area, whose spare parts are not readily available. Mann (2003) found similar results in a study undertaken elsewhere in Southern Africa. During discussions with various stakeholders it was also indicated that there is a lack of technical skills at both the WSP and community levels, and this contributed to delayed repairs and maintenance leading to eventual failure of the SWI. It was observed that once a particular SWI has broken down, the rural 


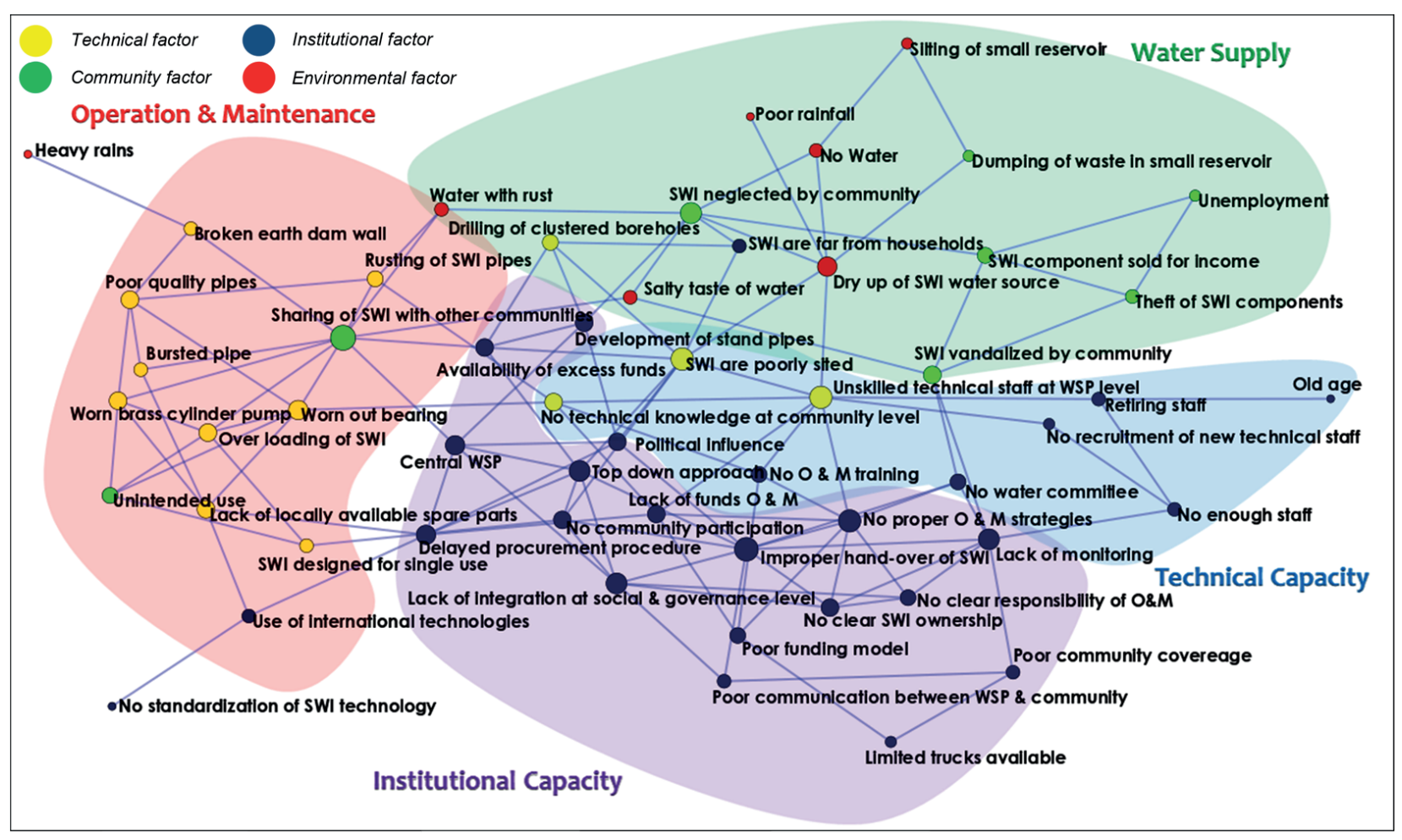

Figure 3

Causes of SWI failure theme and domain network for Makhudutamaga

communities resort to using the next available functional SWI or unprotected water sources. This has proven to be a problem as it results in the overloading of the next available functional SWI and puts rural communities at risk of contracting waterborne diseases. Most SWI observed in the field were designed for single use (e.g., domestic water supply), but rural communities used them for multiple uses (e.g., domestic water supply, garden irrigation, watering small livestock). This also resulted in overloading of the working SWI resulting in it either breaking down or experiencing periodic 'drying out' during the day.

\section{Environmental factors}

Environmental factors had a direct impact on the water supply of the rural communities in Nebo Plateau. Stakeholders indicated that poor or low rainfall resulted in reduced underground and surface-water recharge in the area. As a result, boreholes and small reservoirs used by the rural communities could not supply sufficient water; some did not have water at all during winter as they had dried up. It was observed that, in one case, rural communities used a dried-up small reservoir for dumping of waste material, as a result contributing to its siltation.

In some cases, galvanized pipes used for extraction of underground water from boreholes were corroding due to the minerals in the water, or possibly the use of non-standard materials, thus yielding water with a rusty colour and smell. In some areas, the water from the boreholes tasted salty, thus turning out to be unsuitable for domestic consumption.

\section{Community factors}

The rural community members neglected and vandalised the SWI. This is because the WSP responsible for maintaining the
SWI in Nebo Plateau delayed in repairing the broken-down SWI and the rural communities did not have the knowledge and skills to repair them. Some of the rural community members removed the hand-pump and windmill hardware to sell as scrap metal. This was driven by the lack of employment opportunities in the study area, which has resulted in some community members having to find other means of generating income to sustain their livelihoods.

\section{Institutional factors}

In Nebo Plateau, the WSP is centralized at the district level. This has made it difficult for the rural community members to communicate with the WSP. As a result, a top-down approach is often used by the WSP when implementing SWI development projects in Nebo Plateau, where some of the projects are said to be politically influenced. Due to the top-down approach there has been limited community participation in SWI development projects. This has resulted in unclear ownership and unclear allocation of responsibility for O\&M of SWI.

At the local level, the District WSP has deployed some of their personnel to provide water-related services to the rural communities of Nebo Plateau. However, the WSP personnel have limited resources; (i) aging and not enough staff, (ii) lack of transport to cover the whole area, (iii) no funding for operation and maintenance (O\&M), and (iv) no spare parts to maintain the SWI. At the community level, rural communities do not have water committees that are responsible for handling water-related issues.

\section{Themes of causes of SWI failure}

The theme and domain network (see Fig. 3) represents the complex interactions of different categories of factors affecting 
access to water in the study area. The large nodes shown in the network represent the major causes of SWI failure (critical points) that affect water supply in the study area. Furthermore, themes (4) were identified as a result of the grouping of factors to allow for a thematic analysis of the network. The themes identified were: technical capacity (blue shade), institutional capacity (purple shade), operation and maintenance (red shade) and water supply (green shade). Of the technical and institutional issues, most were to do with capacity. For a systematic interpretation/analysis of the network, the focus will be on the critical points represented by the different themes.

\section{Technical capacity}

The positioning of the factors in the middle of the network indicates that the interaction of the technical and institutional factors forming the theme is central to the causes of failure of SWI in the study area. The lack of unskilled technical staff at the WSP level is the main cause of failure identified in the theme. The factor has a direct relationship with two other main causes of SWI failure in the theme. These factors are poorly sited SWI and lack of technical knowledge at the community level. The behaviour depicted by these factors highlights their importance in improving water supply in the study area. Similar findings arose from a study conducted in the rural areas of Swaziland, which found that technical factors are critical in improving water supply in rural communities (Graciana and Nkambule, 2012). However, the study did not consider the interaction of the technical factors with other factors resulting in the failure of SWI. The main technical factors that caused failure of SWI depicted in the theme have a strong relationship with institutional factors. This is because they are directly connected to most of the institutional factors within the theme and those grouped at the bottom of the network.

According to the interviews conducted, as well as the information documented in the literature (Boshoff, 2009), the lack of technical staff at WSP level is as a result of the formation of new municipalities after 1994, and the transfer of technical staff from the Department of Water Affairs (DWA) to the Sekhukhune District Municipality between 2003 and 2005. The transfer resulted in the loss of experienced staff as some staff members did not want to move from urban areas to the rural and peri-urban areas of Sekhukhune. This meant that the newly formed municipalities were without technical expertise. This, coupled with budget constraints, ageing staff and a non-existent recruitment drive to recruit skilled and young technical staff, contributed to the causes of failure of SWI in the study area. During the interviews, the technical staff from the WSP indicated that they have not received any formal training since their transfer to the Sekhukhune District Municipality. However, when they were still at the DWA, they received technical training every 6 months. Due to the fact that they are ageing and without proper training, they were unable to go out into the rural communities to train community members on the crucial elements necessary to preserve the SWI used for water supply in their communities.

The interaction illustrated by both technical and institutional factors indicates the importance of employing a holistic approach that considers their interactions in solving the causes of SWI failure in the study area. This indicates that, to improve water supply, one should not address the three technical issues identified in the middle of the network in isolation. They should be addressed at the same time as the institutional factors that directly influence them. Therefore, the WSP in consultation with the communities should develop an O\&M strategy that enforces inspection of SWI on a regular basis to ensure that they are properly maintained and operated. The strategy should be backed by a budget and knowledgeable and skilled technical staff to maintain the SWI, who will train users (established water committees) on how to repair minor breakdowns and properly operate the SWI.

\section{Institutional capacity}

The behaviour of the institutional factors indicates complexity as most of them are grouped in one common position in the network. This is because of the high number of directly related institutional factors identified. The improper hand-over of SWI is one of the major causes of SWI failure identified in the theme. During the interviews it was found that most SWI are developed in the study area without consultation with the community members resulting in improper hand-over which leads to failure of SWI. This is supported by studies (Mann, 2003; Harvey and Reeds, 2004; Rietveld, 2012) conducted in other rural areas where it was found that improper hand-over of SWI is a major cause of SWI failure as rural communities do not have a sense of ownership of the SWI. This is linked with other major factors identified to cause failure of SWI in the theme. The use of a top-down approach without consultation of communities, mainly driven by political agendas, worsened by centralized WSP at district level leaving local municipalities without powers, and the lack of a resourced O\&M strategy to ensure monitoring and maintenance of SWI, were found to be the major causes of failure identified in the theme.

The centralized WSA and WSP at the Sekhukhune District Municipality are responsible for water supply in the five local municipalities that fall under the Sekhukhune District. This promotes the 'top-down approach' in water services provision in Nebo Plateau, as all the roles and functions for water service provision are at district level. The Makhuduthamaga Local Municipality, where Nebo Plateau is located, does not have the role or function for water service provision in the rural communities. Although, the WSP have deployed some of their staff to the local municipality, the decisions concerning development of SWI and O\&M are still made at district level. As a result, the community members were not involved in decision making and due to this most of the projects addressing water-related issues were not demand driven. There appeared to be 'silent' campaign projects for political parties in the lead up to elections. After the elections, some of the unfinished works remained incomplete. This resulted in the lack of integration at a social and governance level, between the WSP and rural communities, as was evident from the lack of platforms for the rural communities to report dysfunctional SWI to the WSP. The lack of such platforms resulted in the rural communities having to wait for the WSP to come to the villages. There are also no water committees that are responsible for monitoring of the SWI. During the interviews with the WSP staff, they indicated that they expected the rural communities to do some of the repairs as the SWI belonged to them. This was not the understanding of the rural communities as they regarded the SWI to be owned by Government. The Government is expected to serve the rural communities as per the Water Services Act of 1997. Because of the lack of clear ownership and the WSP not having enough resources (transport and technical staff) to cover all the communities, rural communities often waited for long periods and used the SWI to a point where it finally wore out and broke down. 
The breakdown of SWI is not only caused by the poor monitoring and O\&M. The lack of spare parts and delayed procurement due to the use of international technologies also contributes to SWI failure. The use of the international technologies is caused by the lack of policy that standardizes the SWI technologies in South Africa (Harvey and Reed, 2004). This mainly applies to hand pumps in Nebo Plateau. Different models/brands of hand pumps were observed in the study area. The use of international technologies is also influenced by the World Bank through their poverty reduction strategies that promote economic liberation, which makes importing of international technologies cheaper than using locally manufactured technologies (Harvey and Reed, 2004). This makes it difficult for the local manufactures to compete with the subsidized technologies. This also makes it difficult for supply chain to procure spare parts on time from the service providers.

The current funds for O\&M are provided by the DWA as part of the agreement for the transfer of the SWI. However, the WSP complains that the budget is not enough; this claim is also supported by the literature reviewed (Rietveld et al., 2008 and Boshoff, 2009). The Integrated Development Plan (IDP) (2012) indicates that the lack of funds for O\&M is also caused by the lack of a SWI inventory in Nebo Plateau. This makes it difficult to develop funding models that will enable the allocation of an adequate budget for O\&M. Although the currently available budget is used for the development of stand-pipe taps that do not supply water at the expense of maintenance of existing SWI.

To resolve the problem, issues relating to SWI development, management and use in the study area should be inclusive of all stakeholders to ensure proper hand-over to and ownership by the SWI users. Such an approach will contribute to reduced SWI failure and improved water supply. However, for this to be successful, it will need strong leadership at all levels (district municipality, local municipality and community) and decentralization of power from the district municipality to the local municipality to eliminate issues that culminate from the top-down approach resulting in lack of integration at social and governance level. This will create a platform for proper engagement with all stakeholders at a local level on all issues to do with SWI.

\section{Operation and maintenance}

The operation and maintenance theme constitutes mainly technical factors and some community factors. This indicates that technical factors affect community factors. Sharing of SWI is depicted as the major cause of failure of SWI. This is because most technical factors causing failure of SWI result in sharing of SWI in the study area. When the SWI fails due to technical factors, the community members are forced to share the next available SWI. As a result, the SWI is overloaded and eventually fails due to the high number of water users collecting water from the SWI for intended and unintended uses. Burst pipes and worn-out bearings, depending on the SWI used, are some of the common causes of failure resulting from sharing of the SWI. This is worsened by the lack of locally available spare parts as communities are forced to wait for long periods for the SWI to be repaired. As a result, communities continue using the next available functional SWI until repairs are done. In the case where there is no alternative SWI, they resort to alternative water sources which are sometimes unsafe. The consequences of a lack of spare parts in the study area are supported by literature reviewed (Harvey and Reed, 2004; Graciana and Nkambule, 2012; Rietveld at el., 2012; Swan, 2012).

To resolve the problems presented in the theme, in addition to training technical staff and establishing competent water committees to monitor, maintain and repair SWI, quality spare parts required to repair and maintain SWI should be made available locally to facilitate timely maintenance and repairs.

\section{Water supply}

Critical in the theme is that rural communities neglect SWI mainly as a result of environmental factors. They are neglected because the communities are not able to draw water for their day-to-day activities. Dried up SWI (boreholes or small reservoir) are the major environmental factors that result in failure. This is as a result of poor siting of SWI, and poor rainfall to recharge the water source. It was observed that communities used low-capacity or dried-up small reservoirs as dumping sites for waste leading to siltation. Therefore, when it rains the small reservoirs do not fill up to original capacity resulting in low levels of water. Furthermore, hand-pumps and windmills attached to boreholes that have dried up were vandalised by some members of the communities as they were not supplying water. Some dismantled the SWI components to sell as scrap metal for extra income. To resolve the problem, the WSP should recruit qualified staff to work with contractors in siting of boreholes and small reservoirs. Communities should also be educated about the disadvantages of dumping waste in small reservoirs as it reduces their capacity and poses a health risk.

\section{Synopsis of the network}

The positioning of the different factors in the network and themes was as a result of the complex interactions of the factors resulting in SWI failure. The critical points and themes identified from the network allowed for a systematic and holistic analysis of the causes of failure of SWI. The factors positioned at the centre of the network are critical in addressing SWI failure as they interact with different factors in other themes. The lack of unskilled technical staff at WSP and poorly sited SWI are directly connected to major causes of SWI failure in the technical capacity theme. Both factors are directly connected to other major causes of SWI failures in the other themes. Unskilled technical staff at WSP level (technical factor) are directly connected to two major causes of SWI failure in the institutional capacity theme, i.e., no proper O\&M strategy (institutional factor), and water supply theme, i.e., dried up SWI water source (environmental factor). Poorly sited SWI is directly connected to three major causes of failure in the institutional theme, i.e., political influence (institutional factor), operation and maintenance theme, i.e., sharing of SWI by communities (community factors) and water supply theme, i.e., dried up SWI water source (environmental factor). The behaviour resulting from the interaction of the major causes of SWI failure indicates that any intervention aimed at addressing SWI failure in the study area should move away from the traditional way of addressing different categories of factors separately. For the intervention to achieve its objectives, it should employ a holistic approach that will address all the different categories of factors based on their interaction at the level of a system. 


\section{CONCLUSIONS AND RECOMMENDATIONS}

The theme and domain network analyses can be used as an approach to analyse complex interactions of different categories of factors resulting in SWI failure. Combined with community structure and graph theory they visually and graphically illustrate the interconnectedness and interactions of the factors in the network. The community structure method allowed for identification of themes which made the analysis of the network manageable as it was divided into themes. The graph theory method allowed for identification of critical points in the network to propose solutions for improvement. The combination of the three methods is powerful as it allows for a systematic analysis of the different categories of factors.

The major causes of SWI failure in the study area consisted of a mixed bag of different categories of factors. The lack of unskilled technical staff at WSP (technical factors), poorly sited SWI (technical factors), sharing of SWI by communities (community factors), drying up of SWI (environmental factors) and improper hand-over of SWI (institutional factors) are some of the major causes of SWI failure in the study area, as identified in the theme and domain network. These factors are interconnected and were located at different positions in the network based on their complex interactions. Overall, the complexity of the interaction of the factors that causes the failure of SWI depicted by the network indicates that it will require a holistic approach in addressing SWI- related issues in the study area. It is therefore recommended that similar research should be done in the other municipalities, which fall under the Sekhukhune District Municipality, in order to compare findings and improve water supply in the district.

\section{ACKNOWLEDGEMENTS}

The research reported herein was funded under the Challenge Programme on Water for Food Programme (CPWF) Limpopo Basin Development Challenge (LBDC). We therefore thank the CPWF - LBDC for funding this research and all members of the research project team for their support. The authors would like to extend their appreciation to the communities of Nebo Plateau (Limpopo Province) and the technical and management personnel of the Makhudutamaga Local Municipality (Sekhukhune District), Limpopo Province, for their assistance and provision of important research information. A special thank you goes to Prof Bezuidenhout (formerly University of KwaZulu-Natal) for his assistance with the theme and domain network analysis approach and the Pajek software application.

\section{REFERENCES}

ADANK M (2006) Linking multiple use services and self-supply principle. In: Proceedings of the $5^{\text {th }}$ Rural Water Supply Network Forum on Scaling up Local Entrepreneurship in Rural Water Supply to meet the MDGs, 23-30 November 2006, Ghana.

BATAGELI V and MRVAR A (2016) Analysis and visualization of large networks with program package Pajek. Complex Adaptive Syst. Model. 4 (1). https://doi.org/10.1186/s40294-016-0017-8.

BEZUIDENHOUT CN, BODHANYA S, SANJIKA T, SIBOMANA MS and BOOTE GLN (2012) Network analyses approaches to deal with causal complexity in a supply network. Int. J. Prod. Res. 50 (7) 1840-1849. https://doi.org/10.1080/00207543.2011.575088.

BEZUIDENHOUT CN, MAHAMMAD K and SIBOMANA MS (2013) Using theme and domain networking approach to understand complex agri-industries systems: A demonstration from the South African sugar industry. Outlook Agric. 42 (1) 9-16. https://doi.org/10.5367/oa.2013.0119.

BOSHOFF L (2009) Municipal infrastructure asset care in South Africa: A reality check. URL: http://iatconsulting.co.za/ Publications/Municipal\%20Asset\%20Care\%20in\%20South\%20 Africa_A\%20Reality\%20Check.pdf (Assessed 8 September 2011).

BOWEN GA (2008) Naturalistic inquiry and the saturation concept: a research note. Qual. Res. 8 (1) 137-152. https://doi. org/10.1177/1468794107085301.

CARTER RC, HARVEY E and CASEY V (2010) User financing of rural hand pump water services. In: Proceeding of the IRC Symposium 2010 on Pumps, Pipes and Promises: Cost, Finances and Accountability for Sustainable WASH Services, 16-18 November 2010, Netherlands.

CILLIERS P (1998) Complexity and Postmodernism: Understanding Complex Systems. Routledge, London. 2-3.

CROSS R, NOHRIA N and PARKER A (2002) Six myths about informal networks - and how to overcome them. Sloan Manage. Rev. 43 (3) 67-76. https://doi.org/10.1093/0195165128.003.0004.

DUNGUMARO EW and MADULU NF (2003) Public participation in integrated water resources management: the case of Tanzania. Phys. Chem. Earth 28 (20-27) 1009-1014. https://doi.org/10.1016/j. pce.2003.08.042.

FAIRWEATHER J (2010) Farmer models of socio-ecologic systems: application of causal mapping across multiple locations. Ecol. Model. 221 (3) 555-562. https://doi.org/10.1016/j. ecolmodel.2009.10.026.

FAIRWEATHER J, HUNT L, ROSIN C, CAMPBELL H, BENGE J and WATTS M (2006) Understanding Kiwi Fruit Management Using Causal Mapping. Report No 06/09. Agricultural Research Group on Sustainability Research, Canterbury, New Zealand. ISSN 1177-7796.

FORTUNATO S (2010) Community detection in graphs. Phys. Rep. 486 (3-5) 75-174. https://doi.org/10.1016/j.physrep.2009.11.002.

FREEMAN L (1977) A set of measures of centrality based on betweenness. Sociometry 40 (1) 35-41. https://doi. org/10.2307/3033543.

FREEMAN L (1979) Centrality in social networks: Conceptual clarification. Social Networks 1 (3) 215-239. https://doi. org/10.1016/0378-8733(78)90021-7.

GRACIANA P and NKAMBULE SE (2012) Factors affecting sustainability of rural water schemes in Swaziland. Phys. Chem. Earth 50-52 196-204. https://doi.org/10.1016/j.pce.2012.09.011.

HARVEY PA and REED RA (2004) Rural Water Supply in Africa: Building Blocks for Hand Pump Sustainability. Loughborough University, United Kingdom. 25 pp.

HUISMAN M and VAN DUIJN MAJ (2003) StOCNET: Software for the statistical analysis of social network. In: Proceedings of the $23 \mathrm{rd}$ Biennial Conference of the Society for Multivariate Analysis in the Behavioural Sciences, 1-3 July 2002, Netherlands.

HUNTER PR, POND K, JAGALS P and CAMERON J (2009) An assessment of the cost and benefit of intervention aimed at improving rural community water supply in developing countries. Sci. Total Environ. 407 (12) 3681-3685. https://doi.org/10.1016/j. scitotenv.2009.03.013.

HUTTON G (2013) Global costs and benefits of reaching universal coverage of sanitation and drinking-water supply. J. Health Water 11 (1) 1-12. https://doi.org/10.2166/wh.2012.105.

IDP (Integrated Development Plan) (2012) Integrated Development Plan 2011/2012. URL: http://www.sekhukhunedistrict.gov.za/sdmadmin/documents/Sekhukhune\%202011-12\%20IDP.pdf (Accessed 18 June 2013).

IDP (Integrated Development Plan) (2018) Integrated Development Plan 2017/2018. URL: http://www.makhuduthamaga.gov.za/ documents/MLM\%20APPROVED\%20\%202017-2018\%20IDP.pdf (Accessed 23 February 2018).

KAMADA T and KAWAI S (1989) An algorithm for drawing general undirected graphs. Inf. Process. Lett. 31 (1) 7-15. https://doi. org/10.1016/0020-0190(89)90102-6.

KUSCU H, BOLUKTEPE FE and DEMIR AO (2009) Performance assessment for irrigation water management: A case study in the Karacabey irrigation scheme in Turkey. Afr. J. Agric. Res. 4 (2) 124-132. https://doi.org/10.1002/ird.326. 
MANN E (2003) Sustainable water supply for a remote rural community in Mozambique. Greener Manage. Int. 2003 (42) 55-66. https://doi.org/10.9774/gleaf.3062.2003.su.00008.

MARKS SJ and DAVIS S (2012) Does user participation lead to sense of ownership for rural water systems? Evidence from Kenya. World Dev. 40 (8) 1569-1576. https://doi.org/10.1016/j. worlddev.2012.03.011.

MARTINEZ-LOPEZ B, PEREZ AM and SANCHEZ-VIZCAINO JM (2009) Social network analysis: Review of general concepts and use in preventive veterinary medicine. Transbound. Emerging Dis. 56 (4) 109-120. https://doi.org/10.1111/j.1865-1682.2009.01073.x.

MCCLANAHAN TR, CASTILLA JC and WHITE AT (2009) Healing small-scale fisheries by facilitating complex socio-ecological systems. Rev. Fish Biol. Fish. 19 (1) 33-47. https://doi.org/10.1007/ s11160-008-9088-8.

RIETVELD LC, HAARHOFF J and JAGALS P (2008) A tool for technical assessment of rural water supply systems in South Africa. Phys. Chem. Earth 34 (1-2) 43-49. https://doi.org/10.1016/j. pce.2007.12.001.

ROSENHEAD J and MINGERS J (2005) Rational analysis for a problematic world revisited, problem structuring methods for complexity, uncertainty and conflict. Eur. J. Oper. Res. 161 (2) 75-76. https://doi.org/10.1057/ejis.1991.10.

RSA (Republic of South Africa) (1997) Water Services Act (Act 108 of 1997). Department of Water Affairs and Forestry, Pretoria.

ŠADZEVIČIUS R, DAMULEVIČIUS V and SKOMINAS R (2013) The technical state of earth dams in Lithuania. Environ. Eng. Landscape Manage. 21 (3) 180-188. https://doi.org/10.3846/16486897.2012.662910. SENZANJE A, SIMALENGA TE and JIYANE J (2012) Definition and Categorization of Small-Scale Water Infrastructure: Report No.1. CGIAR Challenge Programme for Water and Food, Agricultural Research Council - Institute for Agricultural Engineering, Silverton, Pretoria.

SILVERMAN D (2002) Qualitative Research Theory, Method and Practice. Sage, London. $125 \mathrm{pp}$.

STERMAN JD (2006) Learning from evidence in a complex world. Am. J. Public Health 96 (3) 505-514. https://doi.org/10.2105/ ajph.2005.066043.

SWAN AD (2012) Low cost telemetry for water applications in rural Africa: A review. In Proceedings of the 12th international WATERNET/ WARFSA/GWP-SA Symposium, 26-28 October 2011, Maputo.

TELESFORD QK, SIMPSON SL, BURDETTE JH, HAYASAKA S and LAURIENTI PJ (2011) The brain as a complex system: Using network science as a tool for understanding the Brain. Brain Connectivity 4 (1) 295-307. https://doi.org/10.1089/brain.2011.0055. WATSON G (2004) The legacy of ishikawa. URL: http://www. gregoryhwatson.eu/images/6-QP_Watson_-_April2004_-_Legacy_ of_Ishikawa.pdf (Accessed 21 November 2014)

XU K, TANG C, TANG R, ALI G and ZHU J (2010) A comparative study of six software packages for complex network research. In: Proceedings of the Second International Conference on Communication Software and Networks, 26-28 February 2010, Singapore. 